\title{
Improvement of Acoustic-Vibration Performance of E. urophylla by High-Temperature Heat Treatment
}

\author{
Ling jing Zhu ${ }^{1,2, a}$, Tao Jiang ${ }^{3, b,}$, Guofu Wu ${ }^{1, c}$ \\ ${ }^{1}$ Guangxi Eco-engineering Vocational and Technical College, \\ 168 Junwu Rd., Liuzhou545004, Guangxi, P. R. China \\ ${ }^{2}$ Northeast Forestry University, Material Science and Engineering College, \\ 26 Hexing Rd., Harbin150040, Heilongjiang P. R. China \\ ${ }^{3}$ Forestry College of Guangxi University, \\ Nanning530005, Guangxi, P. R. China \\ a278076345@qq.com, ${ }^{\text {b* }}$ Corresponding author:jt001@sina.com, ${ }^{c}$ 39002512@qq.com
}

Key words: Eucalyptus urophylla; heat treatment; acoustic performance ; improvement

Abstract. The acoustic-vibration parameters of E. urophylla, including specific Young's modulus $(E / \rho)$, coefficient of sound-radiation resistance $(R)$, and sound resistance $(\omega)$, before and after heat treatment were measured and characterized. Conditions for the heat treatment included $\mathrm{N}_{2}$ as the protection gas and temperatures of $210^{\circ} \mathrm{C}, 220^{\circ} \mathrm{C}$, and $230^{\circ} \mathrm{C}$ with holding times of $2 \mathrm{~h}, 3 \mathrm{~h}$, and $4 \mathrm{~h}$. The results showed that specific Young's modulus, and the coefficient of sound-radiation resistance increased, whereas sound resistance decreased, thereby improving the acoustic performance of the wood. The maximum increments were $9.31 \%$ for specific Young's modulus $\left(210{ }^{\circ} \mathrm{C}, 3 \mathrm{~h}\right)$, and $18.68 \%$ for the coefficient of sound-radiation resistance $\left(230{ }^{\circ} \mathrm{C}, 4 \mathrm{~h}\right)$. Conversely, the maximum decrease in sound resistance was $-11.27 \%\left(230{ }^{\circ} \mathrm{C}, 4 \mathrm{~h}\right)$. Overall, the acoustic-vibration performance of E. urophylla was improved through heat treatment, with the best vibration performance obtained at $230{ }^{\circ} \mathrm{C}$ with a holding time of $4 \mathrm{~h}$.

\section{Introduction}

Eucalyptus is a fast-growing tall tree, but because material of it is generally poor, most can only be used for papermaking. In that case, it cannot bring high economic benefits to the local. Heat treatment degrades hemicelluloses in wood, reducing the hydroxide radicals in the cell wall and weakening the moisture adsorption of wood while improving the dimensional stability and enhancing the resistance to bio-destruction under hypoxic conditions at temperatures at or above $200^{\circ} \mathrm{C}{ }^{[1]}$. Domestic and foreign studies have focused on the influence of heat treatment on the mechanical properties, dimensional stability, and color of wood ${ }^{[2-3]}$, but there have been fewer studies assessing acoustic performance.

Kubojima et al. studied how heat treatment at 120 to $200{ }^{\circ} \mathrm{C}$ for 0.5 to $16.0 \mathrm{~h}$ using $\mathrm{N}_{2}$ or air affects the vibration performance of Sitka spruce. They found that the density of wood decreased with increasing temperature and holding time. In addition, Young's modulus, shear modulus, crystallinity, and crystal grain width initially increased and remained stable at 120 to $160{ }^{\circ} \mathrm{C}$, and then decreased with increasing temperature ${ }^{[5]}$. Jia studied the influence of heat treatment on the acoustic properties of China fir at $120^{\circ} \mathrm{C}$ to $220^{\circ} \mathrm{C}$ with a holding time of $2 \mathrm{~h}$. The researchers determined that the density, Young's modulus, sound resistance, and attenuation coefficient decreased with increasing temperature, whereas the specific Young's modulus and the coefficient of sound-radiation resistance increased. The acoustic property of fir, heat-treated at $220^{\circ} \mathrm{C}$, was superior to that of ancient fir ${ }^{[6]}$. In the high-temperature heat treatment of Metasequoia at 120 to $220^{\circ} \mathrm{C}$ with a holding time of $0.5 \mathrm{~h}$, Sha showed that the heat treatment improved the vibration performance of wood. Specific Young's modulus and cellulose crystallinity notably increased, whereas the attenuation coefficient decreased. Moreover, crystallinity greatly influenced the specific Young's modulus, i.e., the latter increased with 
increasing cellulose crystallinity ${ }^{[7]}$. Zhao et al. studied how heat treatment at 120 to $220{ }^{\circ} \mathrm{C}$ for $0.5 \mathrm{~h}$ affects the vibration performance of China fir. They found that Specific Young's modulus and cellulose crystallinity notably increased, whereas the extractive content and the attenuation coefficient decreased. Overall, The acoustic-vibration performance of China fir was improved through heat treatment ${ }^{[8]}$.

Obviously, determining how to improve the vibration performance of heat-treated wood is important. But there have been fewer studies assessing acoustic performance of the fast-growing wood of Eucalyptus trees. In the present paper, E. urophylla was treated under $\mathrm{N}_{2}$ protection by an ultra-high-temperature heat treatment ${ }^{[9]}$ for various temperatures (greater than $150{ }^{\circ} \mathrm{C}$ ) and holding times. The effect of the high-temperature treatment on the vibration performance of E. urophylla was also considered, with the aim of providing theoretical references for the functional modification of the acoustic performance of the low quality of fast-growing wood.

\section{Experimental}

Materials. Eucalyptus urophylla without any obvious defects was cut into 300 (longitudinal) $\times 30$ (radial) $\times 10$ (tangential) $\mathrm{mm}$ samples with polished surfaces. Before the experiment, the samples were placed in a $20{ }^{\circ} \mathrm{C}$ environment at $65 \%$ relative air humidity and adjusted to the equilibrium moisture content. Nine different treatment conditions were run according to different temperatures and holding times $\left(210^{\circ} \mathrm{C}, 220^{\circ} \mathrm{C}\right.$, and $230^{\circ} \mathrm{C}$ for 2,3 , and $4 \mathrm{~h}$ ), with five samples for each treatment. The parameters of each group of samples were compared before and after heat treatment.

Methods .Measurement of the acoustic performance of wood. Based on the beam theory of the free boundary conditions at both ends ${ }^{[10]}$, the acoustic properties of wood were measured using a two-path, multi-purpose FFT analyzer (CF-5220Z, ONO SOKKI, Yokohama, Japan) by bending vibration and under the critical condition of free ends. A diagram of the experimental set-up is presented in Fig.1. The sample was supported by an elastic tripod at the nodal point with a supporting point ( 0.224 times the total length of the sample) away from one end of the sample. Consequently, the same end or the center of the sample was struck with a blade, so that the sensor at the opposing end would receive the vibration signal. The vibration spectrum was determined using the FFT analyzer and processed with a special software (Visual Basic, Microsoft, Richmond, USA) compiled by Professor Liu Yixing of Northeast Forestry University to examine the vibration performance parameters, including specific Young's modulus, sound resistance, and the coefficient of sound-radiation resistance ${ }^{[11]}$.

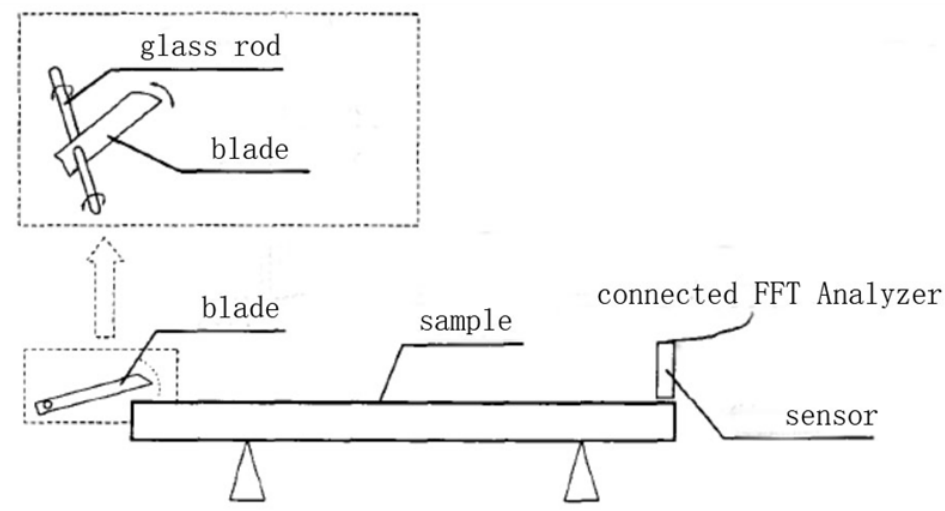

Fig. 1. Diagram of resonance frequency measurements

High-temperature treatment technique .Heat treatment was divided into three stages, as discussed below. The treatment time refers to a constant-temperature holding time. First, during the drying stage, wood samples were preheated in a device under different experimental conditions, and the temperature was raised to $80{ }^{\circ} \mathrm{C}$ over $1 \mathrm{~h}$. Nitrogen was injected into the device, and the temperature was rapidly increased to $103{ }^{\circ} \mathrm{C}$ to dry the samples to a moisture content of approximately $0 \%$. According to the exploratory experimental results related to the heating of $E$. 
urophylla, the temperature holding time lasted approximately $8 \mathrm{~h}$. During the holding-time stage, the temperature was raised to the final treatment temperature and holding time combination of $210{ }^{\circ} \mathrm{C}$, $220^{\circ} \mathrm{C}$, and $230^{\circ} \mathrm{C}$ for $2 \mathrm{~h}, 3 \mathrm{~h}$, and $4 \mathrm{~h}$. Finally, during the cooling and adjusting stage, samples were cooled to below $100^{\circ} \mathrm{C}$ after the heat treatment, and the $\mathrm{N}_{2}$ inlet was discontinued. The general power was shut off when the samples cooled to below $80^{\circ} \mathrm{C}$, and then the samples were collected and placed in a constant temperature humidity chamber to obtain equilibrium moisture content.

\section{Results and discussion.}

Woods for the soundboard of musical instruments should possess adequate acoustic-vibration performance, acoustic-radiation performance, transmission, consumption of vibration energy, and crystallinity $^{[12]}$. The following indicators of vibration performance in E. urophylla were analyzed: specific Young's modulus $(E / \rho)$, coefficient of sound-radiation resistance $(R)$, sound resistance $(\omega)$.

Effect of high-temperature treatment on the Specific Young's modulus. The effects of the heat treatment conditions on the specific Young's modulus are presented in Fig.2.

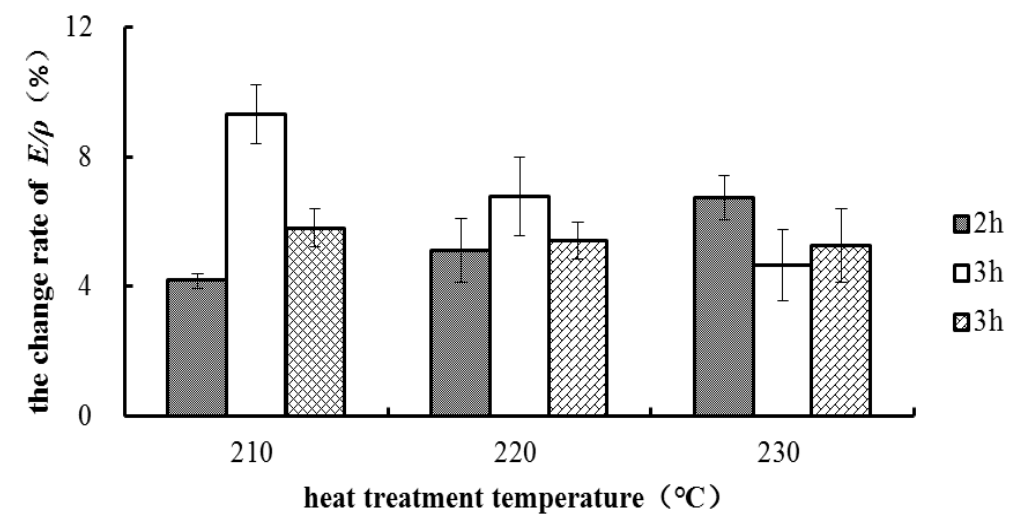

Fig.2. Effect of heat treatment conditions on the specific Young's modulus, E/ $\rho$

The specific Young's modulus, $E / \rho$, is an important physical quantity for evaluating the acoustic vibration performance of wood. A larger $E / \rho$ represents a higher vibration efficiency of wood and a greater suitability for soundboard ${ }^{[13]}$. Fig.2 shows that after heat treatments, the $E / \rho$ of heat treated wood increased the range of $1.4 \%$ to $5.7 \%$, and the values of it ranged from $17.80 \mathrm{GPa}$ to $28.23 \mathrm{Gpa}$. Comparing the heat treatment conditions that the heat treatment temperature was kept constant whereas the holding times were changed, the average increase of $E / \rho(6.91 \%)$ when the holding time was $3 \mathrm{~h}$, was greater than the ones $(5.34 \%, 5.49 \%)$ when the holding times were $2 \mathrm{~h}$ and $4 \mathrm{~h}$. These findings indicate that a proper holding time $(3 \mathrm{~h})$ increased $E / \rho$. Comparing the heat treatment conditions that the holding time was kept constant whereas the heat treatment temperatures were changed, the average increase of $E / \rho(6.43 \%)$ when the heat treatment temperature was $210^{\circ} \mathrm{C}$, was greater than the ones $(5.77 \%, 5.55 \%)$ when the heat treatment temperature were $220^{\circ} \mathrm{C}$ and $230^{\circ} \mathrm{C}$. These findings indicate that a lower heat treatment $\left(\right.$ lower than $210^{\circ} \mathrm{C}$ ) increased $E / \rho$. In this experiment, the rate of change in $E / \rho$ reached a maximum of $9.31 \%$ at $210^{\circ} \mathrm{C}$ with a holding time of $3 \mathrm{~h}$, implying that this condition produced a relatively ideal treatment.

The $E / \rho$ is affected by Young's modulus and density. After high-temperature heat treatment, the orderly structure of cellulose molecules in the amorphous area was crystallized, and some components of hemicelluloses, such as xylan and mannan, were crystallized by the deacetyl reaction. Consequently, the stronger crystallinity improved the Young's modulus ${ }^{[14]}$. During heat treatment, the volatilization of some organics and the degradation of cellulose and hemicellulose reduced the density of E. urophylla, leading to an increased $E / \rho$. However, higher temperature and longer holding time destroyed the crystalline structure, resulting in an amorphous structure, such that the mechanical 
properties (such as Young's modulus) of wood were greatly damaged. Thus, setting the appropriate temperature and time is important.

Effect of high-temperature treatment on the coefficient of sound-radiation resistance.The effect of heat treatment conditions on the coefficient of sound-radiation resistance, $R$, is shown in Fig. 3.

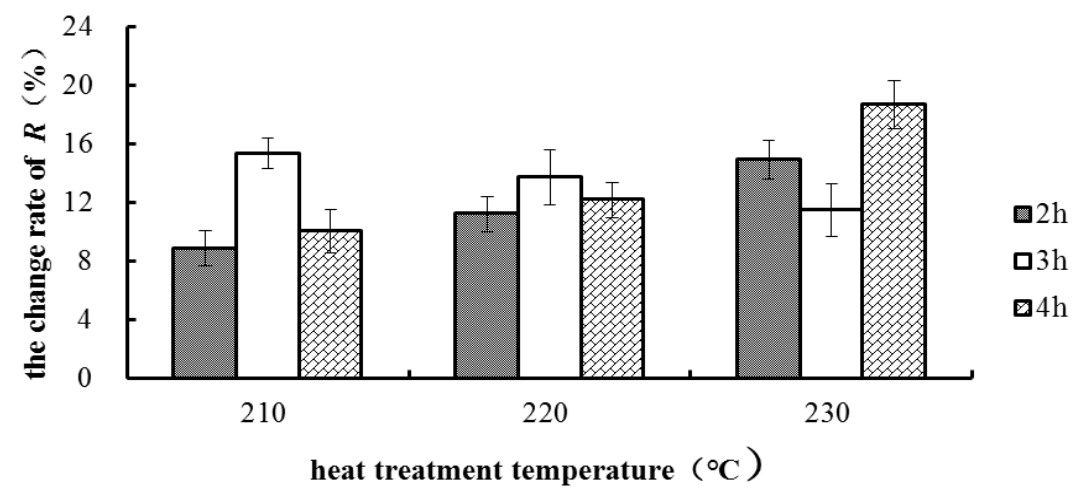

Fig. 3. Effect of heat treatment conditions on the sound-radiation resistance, $R$

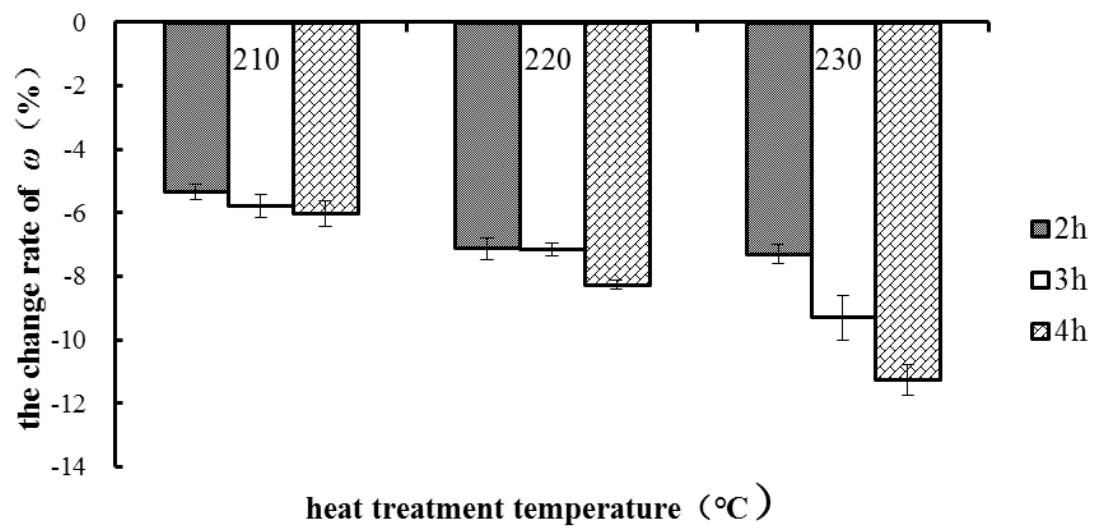

Fig. 4. Effect of heat treatment conditions on the sound resistance, $\omega$

According to the theory of vibration, a larger $R$ results in more efficient vibrations ${ }^{[15]}$. With a larger $R$, the vibration energy can radiate acoustic energy farther, resulting in a higher-volume sound that lasts a longer time.Fig. 3 shows that after heat treatments, the $R$ of heat treated wood increased the range of $8.89 \%$ to $18.68 \%$, and the values of it ranged from $6.82 \mathrm{~m}^{4} / \mathrm{Kg} \bullet \mathrm{s}$ to $9.00 \mathrm{~m}^{4} / \mathrm{Kg} \cdot \mathrm{s}$. Comparing the heat treatment conditions that the heat treatment temperature was kept constant whereas the holding times were changed, the average increases of $R(13.51 \%, 13.63 \%)$ when the holding time were $3 \mathrm{~h}$ and $4 \mathrm{~h}$, were greater than the one (11.67\%) when the holding times was $2 \mathrm{~h}$. These findings indicate that longer holding times $(3 \mathrm{~h} 、 4 \mathrm{~h})$ increased $R$. Comparing the heat treatment conditions that the holding time was kept constant whereas the heat treatment temperatures were changed, the average increase of $R(15.02 \%)$ when the heat treatment temperature was $230^{\circ} \mathrm{C}$, was greater than the ones $(11.42 \% 、 12.37 \%)$ when the heat treatment temperatures were $210^{\circ} \mathrm{C}$ and $220^{\circ} \mathrm{C}$. These results indicated that a higher temperature was necessary to obtain an ideal $R$. Furthermore, the heat treatment temperature of $230{ }^{\circ} \mathrm{C}$ with a holding time of $4 \mathrm{~h}$ achieved the greatest improvement in $R$ $(18.68 \%)$.

The $R$ is affected by Young's modulus and density. If the Young's modulus of wood is larger, the density is smaller, the $R$ value will be greater. For similar reasons of the change of $E / \rho$, in the process of high temperature heat treatment, wood crystallinity will be moderately improved, leading to its Young's modulus is also improved. While in the high temperature heat treatment process, wood density will be reduced, and further improves $R$. 
Effect of high-temperature treatment on the sound resistance. The effect of heat treatment conditions on the sound resistance, $\omega$, is shown in Fig. 4.

The sound resistance, $\omega$, also known as the characteristic resistance, is mainly related to the time response characteristics of vibration. Compared with other solid materials, wood has a smaller $\omega$ and larger $R$, making it a high-quality material for acoustic radiation ${ }^{[14]}$. Figure 4 shows that the high-temperature heat treatment remarkably reduced $\omega$. After heat treatments, the $\omega$ of heat treated wood decreased the range of $-5.34 \%$ to $-11.27 \%$, and the values of it ranged from $2.25 \mathrm{~Pa} \cdot \mathrm{s} / \mathrm{m}$ to $3.87 \mathrm{~Pa} \cdot \mathrm{s} / \mathrm{m}$. Comparing the heat treatment conditions that the heat treatment temperature was kept constant whereas the holding times were changed, longer-holding time resulted in a greater reduction in $\omega$. Furthermore, longer-holding time also resulted in a greater reduction in the average decreased of $\omega$ (Respectively was $-6.59 \%,-7.42 \% 、-8.52 \%$ ). Comparing the heat treatment conditions that the holding time was kept constant whereas the heat treatment temperatures were changed, higher-temperature treatment resulted in a greater reduction in $\omega$. Moreover, higher-temperature treatment also resulted in a greater reduction in the average decreased of $\omega$ (Respectively was $-5.72 \% 、-7.52 \% 、-9.29 \%)$. These results indicated that a higher heat treatment over a longer holding time decreased $\omega$. Given that wood with good acoustic performance exhibits a smaller $\omega$, the heat treatment at $230{ }^{\circ} \mathrm{C}$ with a holding time of $4 \mathrm{~h}$ was ideal, resulting in a maximal reduction in $\omega$ of $-9.29 \%$.

The $\omega$ is affected by the product of Young's modulus and density. If the product of Young's modulus and density is bigger, the value of $\omega$ will be greater, and vice versa. After high-temperature heat treatment, the wood cellulose has a larger crystallinity area, leading to Young's modulus of wood will be enhanced in the early stage of heat treatment process. However, during heat treatment, the volatilization of some organics and the degradation of cellulose and hemicellulose reduced the density of wood, leading to $\omega$ decrease ${ }^{[16]}$.

\section{Conclusions}

1.After heat treatment, the specific Young's modulus $(E / \rho)$ of $E$. urophylla improved by varying degrees. The maximum $E / \rho$ was $9.31 \%\left(210^{\circ} \mathrm{C}, 3 \mathrm{~h}\right)$. The study found that a proper holding time $(3 \mathrm{~h})$ and a lower heat treatment (lower than $210^{\circ} \mathrm{C}$ ) increased $E / \rho$.

2.After heat treatment, the coefficient of sound-radiation resistance $(R)$ of $E$. urophylla improved by varying degrees. The maximum $R$ was $18.68 \%\left(230{ }^{\circ} \mathrm{C}, 4 \mathrm{~h}\right)$. The study found that longer holding times $(3 \mathrm{~h} 、 4 \mathrm{~h})$ and higher temperature $\left(230^{\circ} \mathrm{C}\right)$ was necessary to obtain an ideal $R$.

3.After heat treatment, the sound resistance $(\omega)$ of $E$. urophylla weakened by varying degrees. The maximum reduction of $\omega$ was $-11.27 \%\left(230{ }^{\circ} \mathrm{C}, 4 \mathrm{~h}\right)$. The study found that a higher heat treatment over a longer holding time decreased $\omega$.

4.In summary, the $230{ }^{\circ} \mathrm{C}$ temperature and $4 \mathrm{~h}$ holding time were the best heat treatment conditions for E. urophylla, in which the vibration performance was optimum. In these conditions, $E / \rho$ and $R$ increased by $5.25 \%$ and $18.68 \%$, respectively, whereas the reduction of $\omega$ was $-11.27 \%$.

\section{Acknowledgements}

The authors are grateful for the Project of Promoting the Ability of Young Teachers of the Guangxi Zhuang Autonomous Region (KY2016YB689) for their support of this study.

\section{References}

[1] MARKKU R: Wood heat treatment replacing chemicals, submitted to Asian Timber, Vol. (Sep/Oct), (2004), p.36-38 
[2] J. Bourgois, G. Janin, and R. Guyonnet: The color measurement: a fast method to study and to optimize the chemical transformations undergone in the thermally treated wood, submitted to Holzforschung, Vol. 45(5), (1991), p.377-382

[3] Y. Kubojima, T. Okano, and M. Ohta: Bending strength and toughness of heat-treated, submitted to The Japan Wood Society, Vol.46(1), (2000), p.8-15

[4] W. L. Sun, and J. Li: Analysis and characterization of dimensional stability and crystallinity of heat-treated Larix spp, submitted to Scientia SilvaeSinicae, Vol. 46(12), (2010), p.114-118

[5] Y. Kubojima, T. Okano, and M. Ohta: Vibratinal properties of Sitka spruce heat-treated in nitrogen gas, submitted to Journal of Wood Science, Vol. 44(1), (1998), p.73-77

[6] D. Y. Jia: Effect of High-Temperature Heat Treatment on the Acoustic Properties of China Fir, Master's Thesis, Beijing Forestry University, Beijing, China. (2010)

[7] T. O. Sha: On Influences of High-Temperature/Ultrasonic Pretreatment on the Vibration Properties of Metasequoiaglyptostroboides, Master's Thesis, Beijing Forestry University, Beijing, China, (2015)

[8] M. X. Zhao, L. Kang, and D. M. Chu: Effect of Ultrasound / High-Temperature Heat Treatment on the Acoustic-Vibration Performance of Guqin panel, submitted to Wood Working Machine, Vol. 27 (4), (2016), p.45-50

[9] W. L. Sun, and J Li: Analysis and characterization of dimensional stability and crystallinity of heat-treated Larix spp, submitted to Scientia Silvae Sinicae, Vol. 46(12), (2010), p.114-118

[10] H. Akitsu, M. Norimoto, and T. Morooka:Vibrational properties of chemically modified wood, submitted to Journal of the Japan Wood Research Society, Vol.37(1), (1991), p.590-597

[11] L. J. Zhu, Y. X. Liu, and Z. B. Liu: Effect of High-Temperature Heat Treatment on the Acoustic-Vibration Performance of Picea jezoensis, submitted to Bioresources. Vol. 11(2), (2016), p.4921-4934

[12] Z. B. Liu, Y. X. Liu, J Shen,. and M. Liu: Advances in research and studies on acoustic property of wood for soundboard of musical instrument, submitted to Journal of Northwest Forestry University, Vol.21(3), (2006), p.124-129

[13] Y. X. Liu: Studies on variations of wood vibration properties and influencing factors, in: China Wood Research, edtied by J. Li, Northeast Forestry University Press, Harbin, China, (1998), p.333-354

[14] Z. B. Liu, and J. Shen, in : Vibration Performance of Soundboard Wood and Acoustic Quality of Piano, edtied by Z. B. Liu, Science Press, Harbin, China, (2009)

[15] H. Watanabe, in: Wood Application Basis, Shanghai Scientific and Technical. Publishers, Shanghai, China, (1987)

[16]J. Kohara: Study on the old timber, submitted to Res Rep Fac Eng Chiba Univ, Vol. 9(15), 1958, p. $1-55$ 